\title{
BOLTED CONNECTIONS FOR NON-INTERSECTING H-SECTION BEAM AND COLUMN IN STEEL MOMENT FRAMES
}

\author{
Hiroshi TAGAWA, Shinichiro YOSHIDA, Yudai NAKAOKA, Xingchen CHEN ${ }^{\star}$ \\ Graduate School of Engineering, Hiroshima University, Higashi-Hiroshima, Japan
}

Received 24 October 2018; accepted 18 January 2019

\begin{abstract}
This research proposes connection configurations of two types for non-intersecting $\mathrm{H}$-section steel beam and column. To elucidate the mechanical behavior of the proposed connections, full-scale moment connection tests and finite element analyses were conducted using T-shaped partial frame models. Comparisons between the proposed connections and regular intersecting connections demonstrate that the proposed connection is able to provide sufficient stiffness and energy-dissipation capacity if the beam and column flanges are designed to provide sufficient shear resistance. Then to understand the global behavior of frames using the proposed connections, pushover analyses of a two-story two-span frame were conducted. Because the bending moment of the beam acts on the column by a torque through the proposed connections, torsion spring models were incorporated for representing the proposed connections in 3D frame analysis. Analysis results showed that the girders and columns exhibited lower stiffness and strength than those of frames with intersecting connections because of torsion. To overcome this issue, torsion restraint by secondary beams with different configurations was discussed and optimal configuration was suggested. By utilizing the optimal configuration, torsion of girders and columns can be efficiently reduced into a similar level as that of regular intersecting connections.
\end{abstract}

Keywords: bolted connections, finite element analysis, 3D frame behavior, full-scale cyclic loading tests, non-intersecting beam and column, torsion spring model, eccentric connections.

\section{Introduction}

For smooth force transmission in steel moment resisting frames, it is preferred that beam members be connected to columns without eccentricity. Nevertheless, eccentric beam-to-column connections are used increasingly in steel structural buildings. For example, girders attached with exterior walls are often connected to square hollow section columns with eccentricity for easier installation of walls. The structural behavior characteristics of such eccentric connections have been investigated (Masuda, Tanaka, Ishimaru, Hirai, \& Sasaji, 2000; Miki, Yamada, Kishiki, Jiao, \& Hasegawa, 2015; Shi \& Fan, 2018). In addition to hollow section columns, H-section column-to-eccentric beam connections have also been investigated (Liu \& Tagawa, 2009). Some researchers studied structural behaviors of connections between concrete filled square tubular steel column and eccentric steel beam (Oshida et al., 2005), and the behaviors of reinforced concrete column and eccentric steel beam (Soya, Sato, Komuro, Yasuda, \& Nishimoto, 2010). Furthermore, eccentric connections in reinforced concrete structures have been studied exten- sively (Vollum \& Newman, 1999; Lafave, Bonacci, Burak, \& Shin, 2005; Canbolat \& Wight, 2008; Asran, El-Esnawi, \& Fayed, 2017).

Besides common eccentric beam-to-column connections by which the beams intersect with the columns, nonintersecting beam and column connections are used in some steel building structures. Connections of this type are adopted according to architectural demands such that the column members are allocated outside of the rooms. Yamada, Yoshie, Kouno, and Kojima (2010) investigated the structural performance of non-intersection type steel beam-to-column connections in which square hollow section columns were considered. In that study, the torsional behavior of a bracket between a non-intersecting beam and column was examined. Good performance of those connections was demonstrated through loading tests and numerical analyses.

Mirghaderi and Renani (2008) investigated rigid beamcolumn connections in which two continuous beams were welded to both sides of a built-up box section column with

*Corresponding author. E-mail:xchen@hiroshima-u.ac.jp

This is an Open Access article distributed under the terms of the Creative Commons Attribution License (http://creativecommons.org/licenses/by/4.0/), which permits unrestricted use, distribution, and reproduction in any medium, provided the original author and source are credited. 
some steel plates. Two beam allocations are able to reduce the influence of eccentricity. That study aimed to improve the rigidity of the Khorjini connections because the recent earthquakes induced damage in steel structures with that type of connections.

This paper presents a proposal of bolted connections for non-intersecting beams and columns in steel moment frames to meet the architectural demands such that the column members are out of sight in the room. Utilization of bolts rather than welds for connections can facilitate the connection process at the construction site. It is noteworthy that the $\mathrm{H}$-section columns that are rather popular are considered here, in contrast to almost all earlier studies related to the eccentric connections in which hollow section columns were considered. In this study, first, the structural characteristics of the proposed connections were examined through loading tests for T-shaped partial frame specimens. Then more detailed discussions were put forward based on finite element analysis (FEA). Large eccentricity in the connections can influence the elastic-plastic behavior of moment-resisting frames, especially when using H-section columns. Therefore, pushover analyses were performed for three-dimensional frame models including the proposed connections. For the 3D frame analysis, the torsion spring is applied in modeling the proposed connection for reduction of the computational load. Based on the analysis results, configurations of the secondary beam were discussed on restraining the torsion of girders and columns attributable to non-intersecting connections.

\section{Outline of proposed connections}

Figure 1 shows the proposed connection configurations of two types which were investigated for the non-intersecting $\mathrm{H}$-section steel beam and column. In both configurations, the beam is connected to the column by a connection plate. This figure exhibits one benefit of the proposed non-intersecting connections in which the beam member need not be separated for connecting to both sides of the column. This could simplify the manufacture as well as the on-site assembly of steel members.

In the Type A configuration, the connection plate is welded to the column flanges. It is then bolted to the flanges and web of the beam. Figure 1(a) shows that two horizontal plates and one vertical plate are welded on the connection plate as a prefabricated component. The beam flanges and web are bolted, respectively, to the horizontal plates and vertical plate with additional angle members. Steel angles are often used for the connection components (Eurocode 3,2005$)$. They are also applied for reinforcement in bolted connections (Grogan \& Surtees, 1999; Tagawa \& Liu, 2014). Two stiffening plates are welded between the column flanges at the same level as the beam flanges and are further welded to the connection plate (hidden in the figure) to transmit shear force from the beam flange to the column.

The Type B configuration, proposed for improvement of the connection procedure presented in Figure 1(b), shows that two octagonal connection plates are welded to both beam and column flanges during fabrication. In the same way as Type A, two stiffening plates are welded
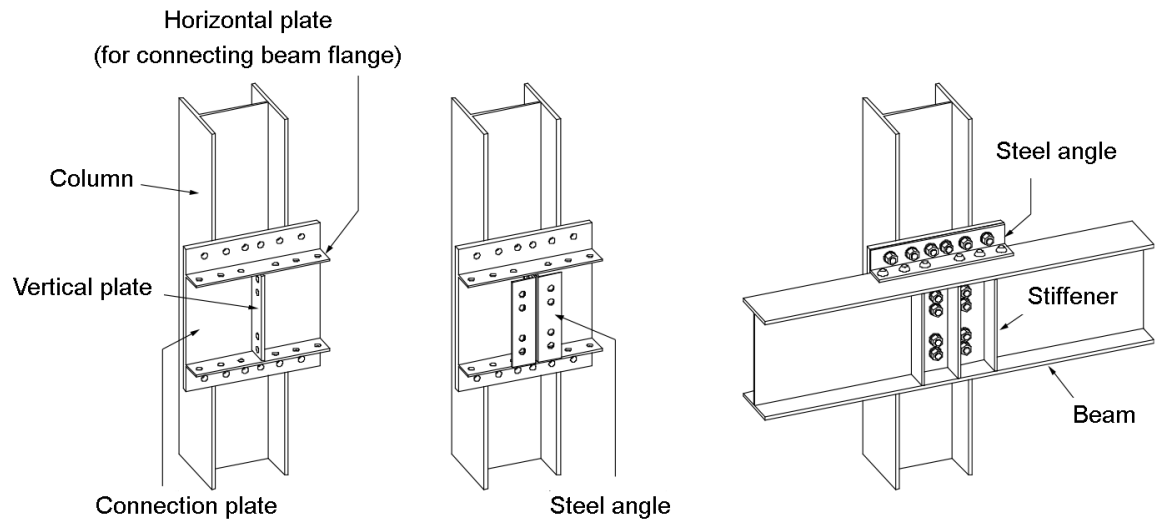

(for connecting beam web)

(a)
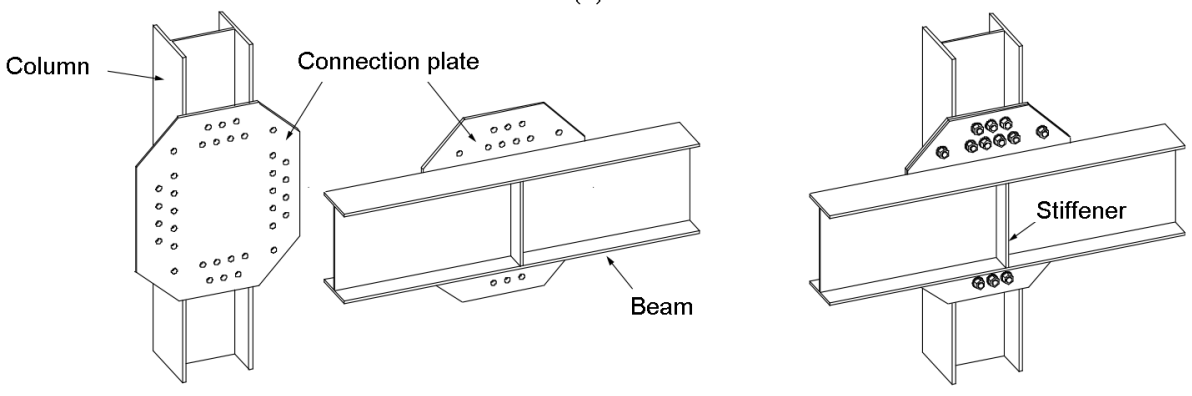

(b)

Figure 1. Scheme of the proposed connections: (a) Type A; (b) Type B 


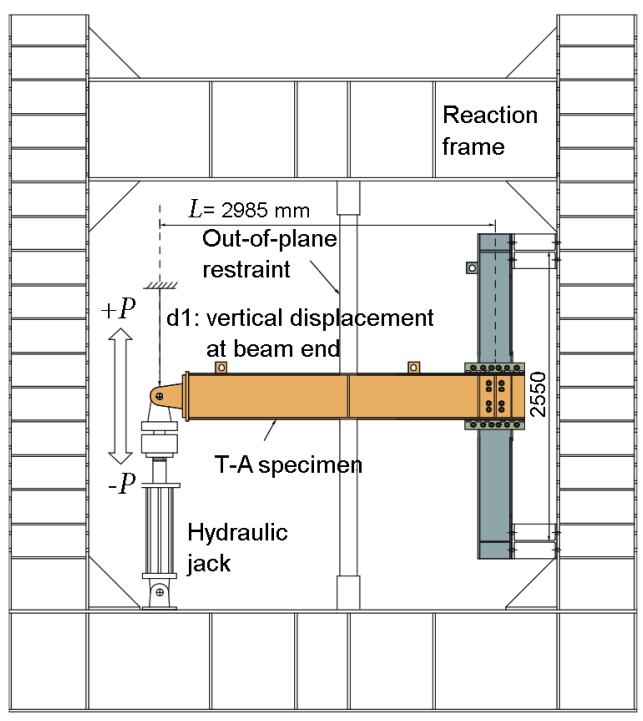

(a)

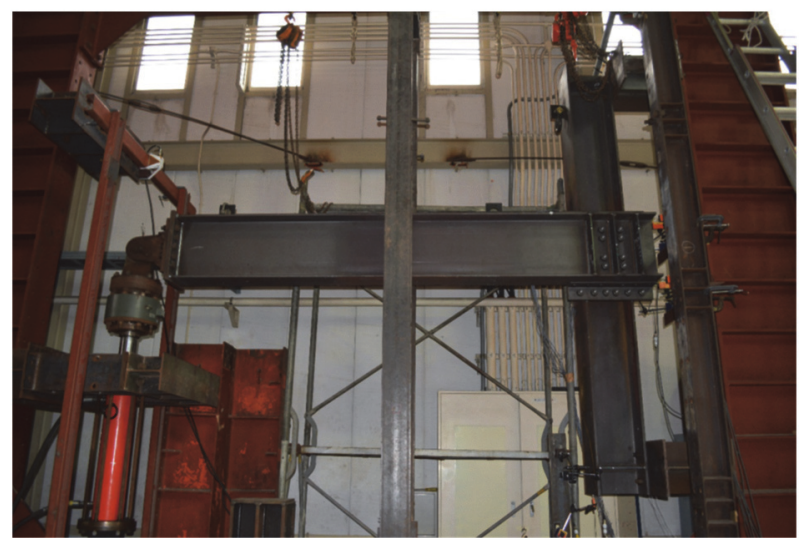

(b)

Figure 2. Test setup: (a) setup scheme (specimen T-A as example); (b) photograph of the test setup

between the column flanges at the same level as the beam flanges and are further welded to the connection plate (hidden in the figure). The task left at the construction site is merely the connection of the two plates using highstrength bolts. This is one advantage of Type B against Type A which utilizes several bolted angle members.

\section{Cyclic loading tests}

To validate the mechanical behavior of the proposed connections, two full-scale connection tests were conducted for Type A and Type B.

\subsection{Test program}

\subsubsection{Specimens}

Figure 2 shows the experimental configuration in which the T-shaped partial frame specimen is set up in the reaction frame. The column section of $\mathrm{H}-300 \times 300 \times 10 \times 15$ (H-depth $\times$ flange-width $\times$ web-thickness $\times$ flange-thickness) and the beam section of $\mathrm{H}-400 \times 200 \times 8 \times 13$ were used for both tests. The connection geometry is presented in Figures 3(a) and 3(b). Both specimens were designed according to the strong column-weak beam principle. As for specimen $\mathrm{T}-\mathrm{B}$, the beam and column flanges were strengthened to ensure that all of the elements around the connection area could remain elastic and the plastic hinge was expected to occur in the beam. As for specimen T-A, in order to examine the collapse mechanism of the proposed connection, the beam and column flanges were not strengthened at the connection area.

In specimen T-A whose component names have been presented in Figure $1(\mathrm{a})$, the connection plate $(580 \times 525)$ thickness was $28 \mathrm{~mm}$ determined based on Eqn (1). The thickness of the vertical plate $(90 \times 346)$ was $12 \mathrm{~mm}$, and a pair of angle members connected with the vertical plate were L- $90 \times 90 \times 6$ (L-depth $\times$ width $\times$ thickness). The thick- nesses of these members associated with the vertical plate were determined considering the beam web thickness of $8 \mathrm{~mm}$. The thickness of the horizontal plate $(90 \times 525)$ was $9 \mathrm{~mm}$, and the top and bottom angle members connected with the beam flange were L- $90 \times 90 \times 10$. The thicknesses of these members associated with the horizontal plates were determined considering the beam flange thickness of $13 \mathrm{~mm}$. The angle members were fabricated from SS400 steel. The other members were SN400B steel. Bolts for connecting the beam flanges to the connection plate were super high-strength friction bolts (S14T M20), and bolts for other connections were high-strength friction bolts (S10T M22). Bolt F3, as depicted in Figure 3(a), was not used because of space shortages. The other five bolts were verified by calculation as able to provide sufficient shear resistance.

In specimen $\mathrm{T}-\mathrm{B}$, the thickness of two connection plates welded to the beam and column flanges was $19 \mathrm{~mm}$. The column flanges were strengthened by plug welded cover plates $(723 \times 280)$ of $9 \mathrm{~mm}$-thickness. The beam flanges were also strengthened by plug welded cover plates $(605 \times 180)$ of $9 \mathrm{~mm}$-thickness. Strengthening cover plates were used to avoid shear yielding of the beam and column flanges during tests and their thicknesses were determined based on Eqn (3). To ensure the cover plate efficacy, groove welds were conducted for connecting the cover plate and flanges to the connection plates, as depicted in Figure 3(b). All the members were fabricated from SN400B steel. All the bolts were super high-strength friction bolts (S14T M20). Material properties of the members are presented in Table 1.

Regarding the design of test specimens, the connection plate thickness was determined based on the same concept as the panel zone design to maintain elasticity during tests, as expressed by Eqn (1):

$$
\frac{\alpha M_{b p}}{d_{c} \cdot d_{b} \cdot t_{j}} \leq \frac{\sigma_{j y}}{\sqrt{3}},
$$


Table 1. Material properties

\begin{tabular}{|l|c|c|c|c|c|c|}
\hline & \multicolumn{3}{|c|}{ Specimen T-A } & \multicolumn{3}{c|}{ Specimen T-B } \\
\hline & $\begin{array}{c}\text { Yield stress } \\
\left(\mathrm{N} / \mathrm{mm}^{2}\right)\end{array}$ & $\begin{array}{c}\text { Ultimate stress } \\
\left(\mathrm{N} / \mathrm{mm}^{2}\right)\end{array}$ & $\begin{array}{c}\text { Elongation } \\
(\%)\end{array}$ & $\begin{array}{c}\text { Yield stress } \\
\left(\mathrm{N} / \mathrm{mm}^{2}\right)\end{array}$ & $\begin{array}{c}\text { Ultimate stress } \\
\left(\mathrm{N} / \mathrm{mm}^{2}\right)\end{array}$ & $\begin{array}{c}\text { Elongation } \\
(\%)\end{array}$ \\
\hline Beam & 304 & 433 & 26 & 328 & 454 & 29 \\
\hline Column & 320 & 438 & 35 & 333 & 432 & 34 \\
\hline
\end{tabular}

where $t_{j}$ is the connection plate thickness. $M_{b p}$ is the plastic moment of the beam section. $\alpha$ is the overstrength factor. $\alpha=1.3$ (AIJ, 2012) was adopted in this study. $d_{c}$ is the distance between the center of column flanges. $d_{b}$ is the distance between the center of beam flanges. $\sigma_{j y}$ is the yield stress of the connection plate.

Sizes and numbers of high-strength bolts were determined to transmit shear force without slippage. For specimen T-A, the bolts of the beam flange and those of the beam web were determined separately. For the beam flange connection, the bolts were determined considering the expected beam flange force. For the beam web connection, the bolts were determined considering the expected beam shear force. For specimen T-B, the bolts for connecting two connection plates as presented in Figure 1(b) were determined by the conventional design equation as:

$$
R_{\max }=\sqrt{R_{M}^{2}+R_{Q}^{2}} \leq R_{f},
$$

where $R_{\max }$ is the maximum bolt shear force among the bolts. $R_{M}$ is the maximum bolt shear force induced by the expected beam bending moment. $R_{Q}$ is the bolt shear force induced by the expected beam shear force. $R_{f}$ is the allowable bolt shear force per bolt.

In specimen $\mathrm{T}-\mathrm{A}$, the beam and column flanges are not strengthened and might yield due to shear force in the connection area as demonstrated by finite element analysis presented in Section 3. On the contrary, cover plates were welded to the flanges around connections in specimen
T-B. The required thickness of the cover plate was determined so that the expected flange force can be transmitted to the connection plate by shear without yielding, as expressed by Eqn (3):

$$
\frac{\alpha M_{b p}}{d_{c} \cdot d_{b} \cdot\left(t_{b f}+t_{c p}\right)} \leq \frac{\sigma_{b y}}{\sqrt{3}},
$$

where $t_{b f}$ is the beam flanges thickness. $t_{c p}$ is the cover plate thickness. $\sigma_{b y}$ is the yield stress of the beam flanges and assumed to be the same as that of the cover plates.

The connection design of the test specimens employed Eqns (1)-(3). In the test specimens, the torsional effect was reduced because out-of-plane movement of the beam was restrained by braces and the column-ends were fully fixed as described later. As for an actual frame design with the proposed connections, torsional effect generated by the eccentric loading pass might not be neglected on the joint behavior as examined in Section 4. Therefore, inspection of the stress state of the connections as well as structural members is needed in the frame design by numerical analysis of the 3D frame model as presented in Section 4.

\subsubsection{Test setup and loading protocol}

A schematic diagram and photograph of the test setup are presented in Figure 2. The top and bottom of the column were fixed completely to the reaction frame. The vertical force $P$ was applied using a $1000 \mathrm{kN}$ hydraulic jack at the cantilever end of the beam (upward is assigned as the

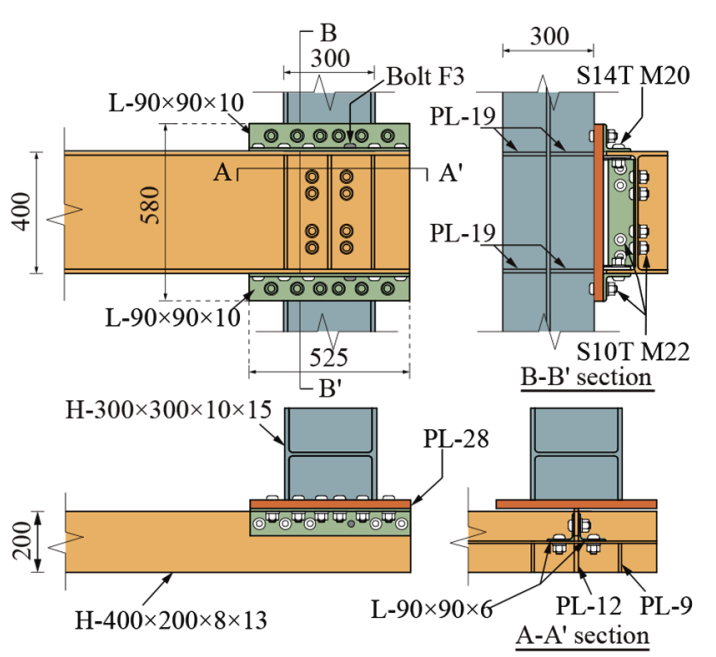

(a)

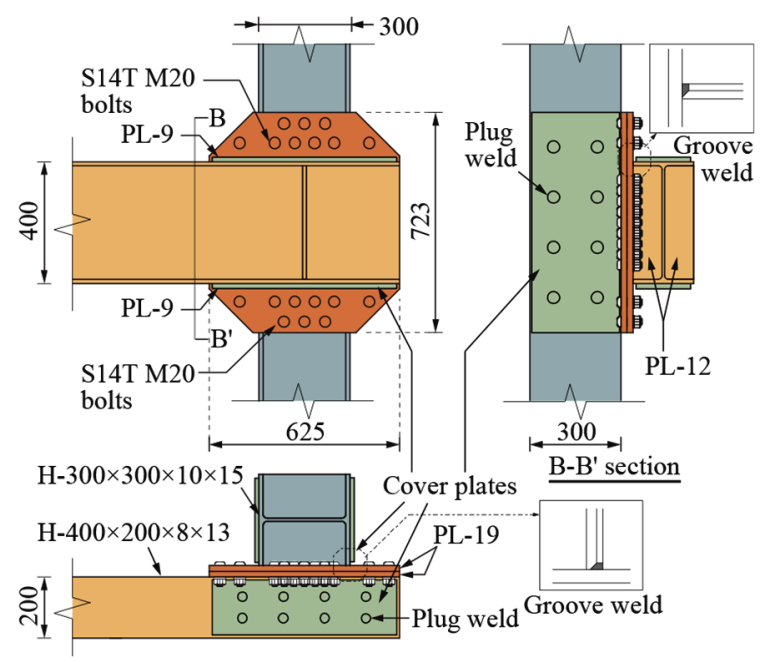

(b)

Figure 3. Connection details (units: $\mathrm{mm}$ ): (a) specimen T-A; (b) specimen T-B 


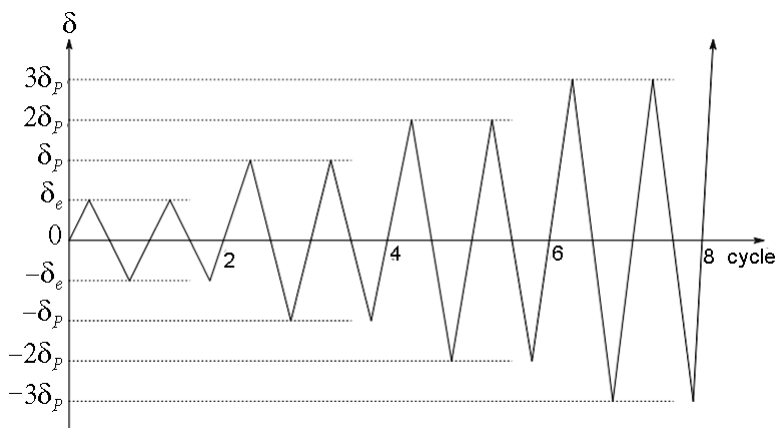

Figure 4. Loading protocol

positive direction). A pair of braces was used to restrain out-of-plane movement of the beam. It is noteworthy that the boundary conditions for the loading test were given to exhibit the connection behavior characteristics such as rigidity and ductility. Eccentricity effects on frame behavior are discussed in Section 4.

The loading protocol is portrayed in Figure 4. First, the loading was force-controlled and was applied in one level with two cycles. The applied force was equal to $25 \%$ of the predicted force when full-section plasticity was developed in the beam. The peak vertical displacement at the loading point is denoted by $\delta_{e}$. Then, the test control was changed to be displacement-controlled based on the vertical displacement at the loading point. Two cycles of loading were examined for each displacement level of $\delta_{p}, 2 \delta_{p}$, and $3 \delta_{p}$. Here, $\delta_{p}$ corresponds to the state when the fullsection plasticity was developed in the beam, as predicted based on the force-displacement relation obtained from the elastic loading cycle $\left(\delta_{p}=4 \delta_{e}\right)$. After those loading cycles, loading was continued until the jack reached its limit in the positive direction.

\subsubsection{Instrumentation}

The instrumentation for specimens T-A and T-B is presented in Figure 5. A displacement sensor d1, which was attached to the pin end of the specimen, was used to measure the vertical displacement and to control the load- ing process. Three pairs of horizontal displacement sensors were arranged to monitor the rotation of each connection component. $\mathrm{d} 2$ and $\mathrm{d} 3$ were used to monitor the rotation at the beam web. $\mathrm{d} 4$ and $\mathrm{d} 5$ were used to monitor the rotation at the column web. To monitor the rotation at the connection plate, $\mathrm{d} 6$ and $\mathrm{d} 7$ were used. Strain gauges were arranged at crucially important locations of the beam flange (B1-B5) and column flange (C1-C5), and at the connection area of the beam flange (B6-B8).

The rotation angle at beam web $\theta_{b}$, column web $\theta_{c}$, and connection plate $\theta_{j}$ were calculated using Eqns (4)-(6):

$$
\begin{aligned}
& \theta_{b}=\frac{d_{3}-d_{2}}{h_{b}^{d s}} ; \\
& \theta_{c}=\frac{d_{5}-d_{4}}{h_{c}^{d s}} ; \\
& \theta_{j}=\frac{d_{7}-d_{6}}{h_{j}^{d s}},
\end{aligned}
$$

where $d_{2}$ to $d_{7}$ respectively represent the displacement values measured by displacement sensors $\mathrm{d} 2$ to $\mathrm{d} 7$. In addition, $h_{b}^{d s}, h_{c}^{d s}$, and $h_{j}^{d s}$ respectively denote the vertical distances between the horizontal displacement sensors attached to the beam, column, and connection plates. Detailed discussion of those rotation angles is put forward in the subsequent section related to FEA.

\subsection{Test results}

\subsubsection{Relation between the load and displacement}

Figures 6(a) and 6(b) respectively present the relation curves of the global load $P$ applied at the beam end and the global relative rotation $R$ of the beam in specimens T-A and T-B. Here $R=d_{1} / L-\theta_{c}$. $L$ is the lateral distance from the loading point to the column center line, as presented in Figure 2(a). The thick dashed lines show the predicted loading level when the beam reaches full-section plasticity at the connection plate edge based on the material property as shown in Table 1. In general, both specimens exhibit sufficient plastic deformation capacity. However, slippage
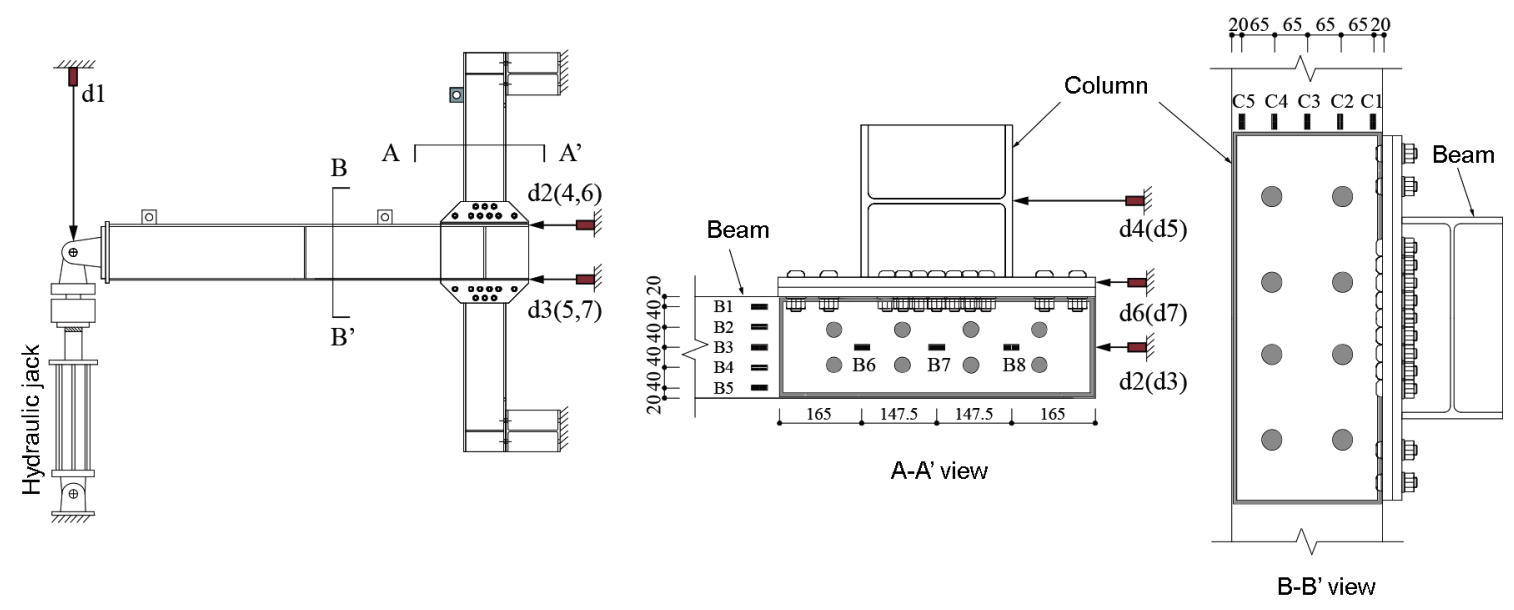

Figure 5. Instrumentation plan 


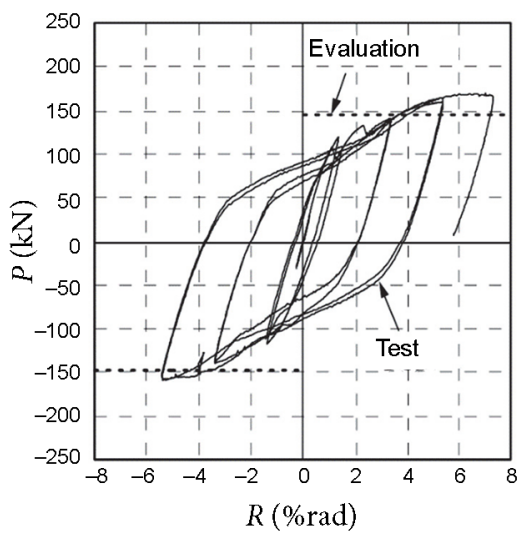

(a)

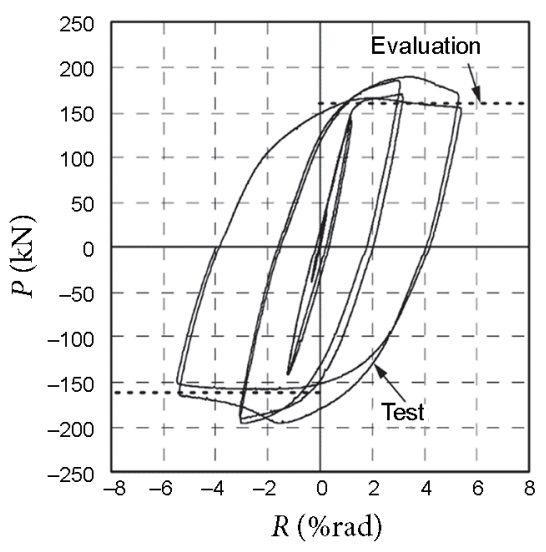

(b)

Figure 6. Relation between vertical load and global relative rotation of the beam:

(a) specimen $\mathrm{T}-\mathrm{A}$; (b) specimen T-B

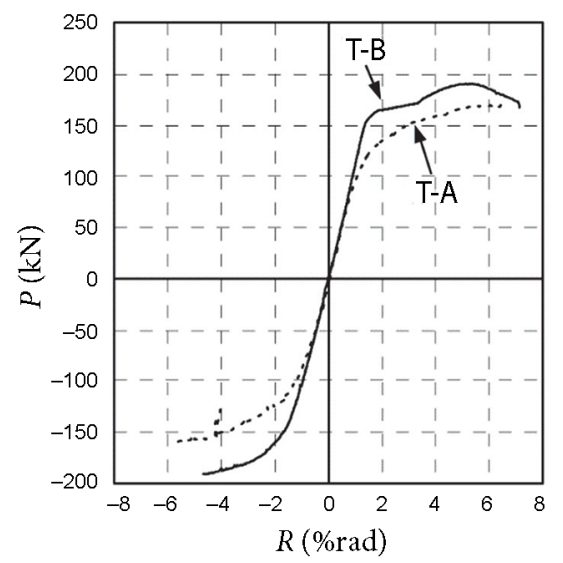

Figure 7. Skeleton curve of relation between vertical load and global relative rotation of the beam

behavior was observed in specimen T-A. This slippage is caused mainly by bolt slippage followed by shear yielding of the beam flanges, as confirmed using the numerical analysis described in Section 3.3.1. This behavior caused strength reduction from the predicted strength level. By contrast, the hysteretic loop in specimen T-B was preferred. In the last two cycles, strength reduction by local buckling of beam flanges was observed (see Figure 8(b)).
Figure 7 presents skeleton curves of global load and displacement relation. Specimen T-B displays higher strength, by which the flanges around the connection were strengthened with cover plates. Figure 8 presents photographs of connections at the final stage of loading. In specimen T-A, slight local buckling of the upper beam flange appeared. Bolt slippage between the beam flange and angle member was observed, as indicated by an arrow. In specimen T-B, large local buckling of the beam flange appeared, whereas the connection deformation and bolt slippage were entirely suppressed.

\subsubsection{Strain distribution on beam and column flanges}

Figures 9(a) and 9(b) present strain distributions on the beam flanges at each load level until the vertical displacement reached $\delta_{p}$ for the first time. As can be seen from the distribution of B1-B5, yielding occurred earlier at locations closer to the connection plate, particularly in specimen T-A. The strain distributions in specimen T-B were uniform.

Among the strain gauges along the center line of the beam (B3, B6-B8) as presented in Figure 10, the strain value of B6 in specimen T-A exceeded the yield strain earlier than that of B3 located outside of the connection area, which was not preferred in the connection design. In specimen $\mathrm{T}-\mathrm{B}$, the connection area remained elastic. The strain

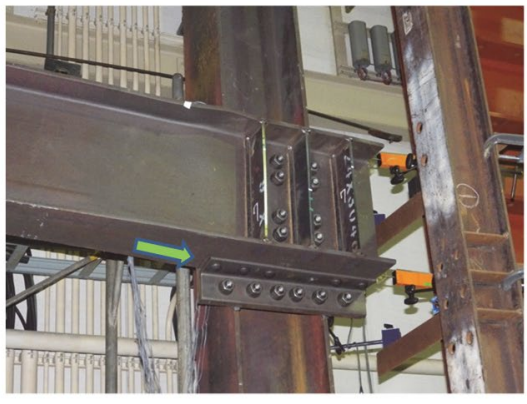

(a)

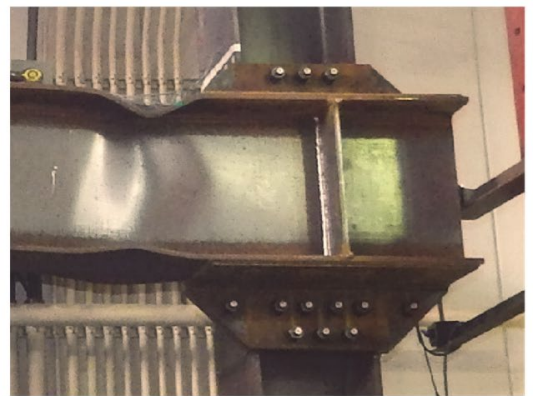

(b)

Figure 8. Deformation of test specimens at the final stage of loading: (a) specimen T-A; (b) specimen T-B 


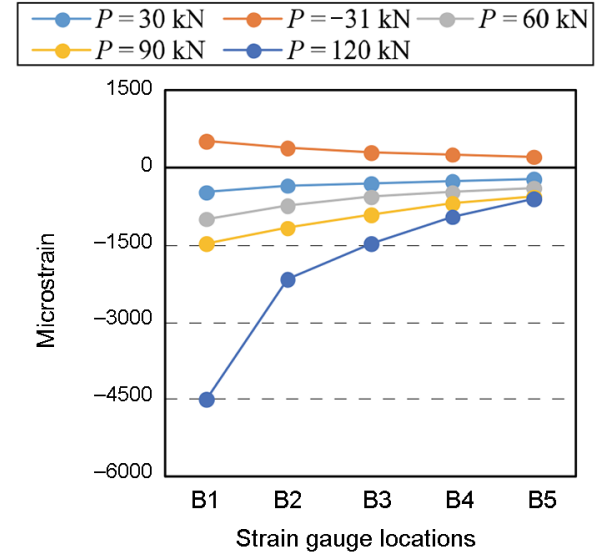

(a)

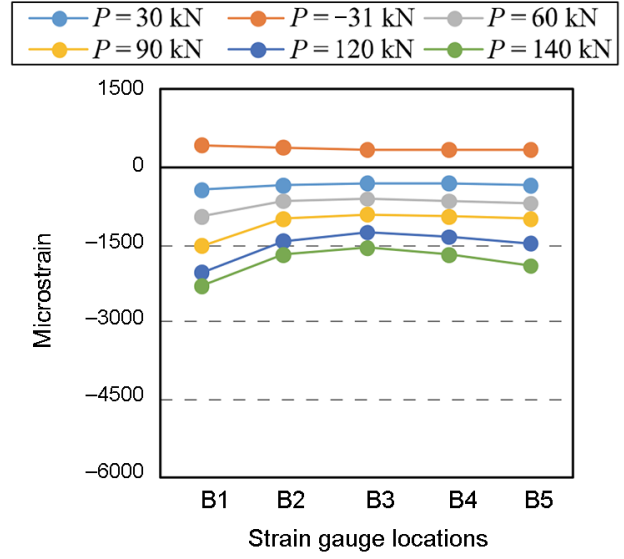

(b)

Figure 9. Variation of strains at locations B1-B5 in the beam flange: (a) specimen T-A; (b) specimen T-B

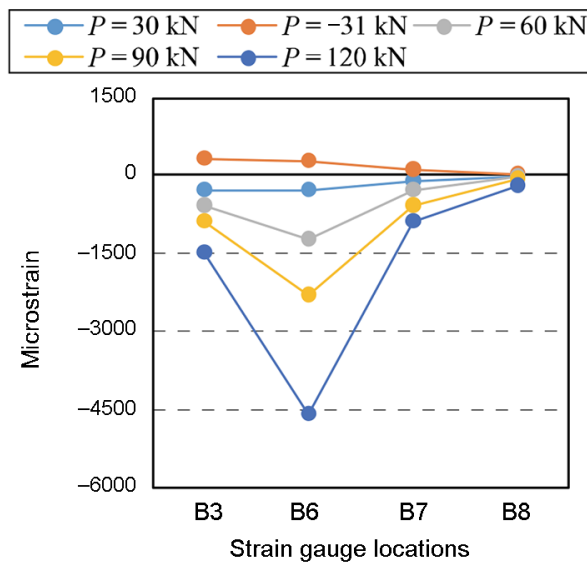

(a)

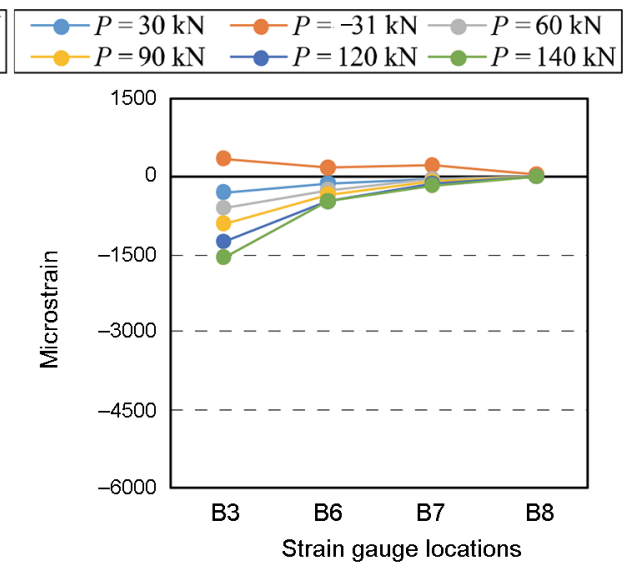

(b)

Figure 10. Variation of strains at locations B3 and B6-B8 in the beam flange:

(a) specimen T-A; (b) specimen T-B

values were much smaller than that outside of the connection area. These behaviors of specimen T-B observed in Figures 9 and 10 are attributable to the cover plates welded on the flanges.

Strains at the column flange as presented in Figure 11 confirmed that the column remained elastic. Similar strains were recorded for specimens T-A and T-B.

\section{Finite element analysis (FEA) of T-shaped partial frames}

To investigate the detailed characteristics of the proposed connections, FEA was conducted for the T-shaped partial frame used for the loading tests. Moreover, a model with a regular connection for an intersecting beam and column was analyzed for comparison. Large eccentricity in the non-intersecting connections can influence the elasticplastic behavior of moment-resisting frames. Therefore, pushover analysis results will be examined in Section 4 for $3 \mathrm{D}$ frame models including the proposed connections.

\subsection{Analysis models and setting}

This study uses simulation software ANSYS 15.0 (2014). Figure 12(a) shows the analysis model corresponding to the test specimens. Figure 12(b) shows the analysis model with the regular connection in which the beam intersects with the column. Welded and bolted connection details were not considered in either T-A or T-B models. In the T-A model, the angle members used for the connection were not modeled. Instead, the beam flanges were extended and connected directly to the connection plate. The vertical plates were extended and connected directly to the beam web. In the T-B model, the beam and column flanges in the connection area were thickened by $9 \mathrm{~mm}$ considering the cover plates; others remained identical to the T-A model. Regarding the regular connection model (the IS model) presented in Figure 12(b), the beam and column flanges were not strengthened, whereas the column web in panel zone was thickened to prevent shear yielding. 


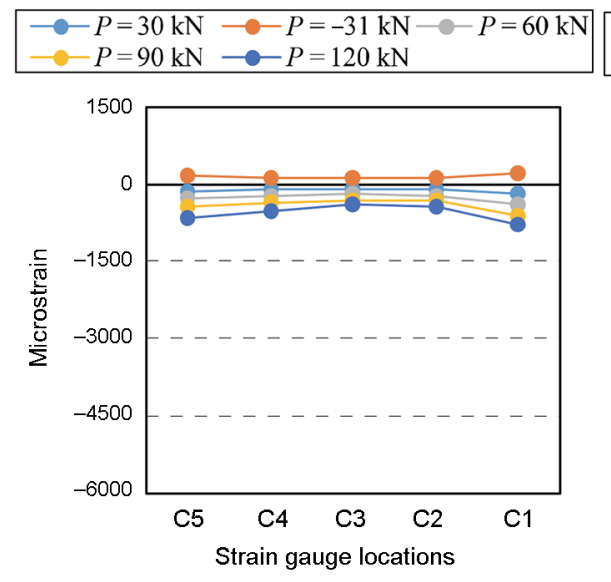

(a)

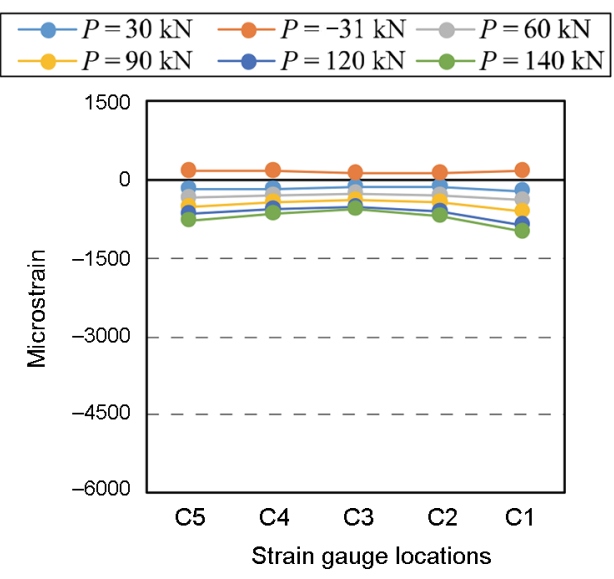

(b)

Figure 11. Variation of strains at locations C1-C5 in the column flange: (a) specimen T-A; (b) specimen T-B

The beams, columns, and connection plates were modeled by the shell 181 element in ANSYS. Young's modulus was $2.05 \times 10^{5} \mathrm{~N} / \mathrm{mm}^{2}$. Poisson's ratio was 0.3 . A bilinear stress-strain relation with a hardening ratio of 0.01 was adopted for the steel material. Formation of yielding follows the Von Mises law. Yield stresses of the beam and column materials were assigned just as those in the T-A specimen. All degree-of-freedoms of the nodes at the top and bottom ends of the column were fully constrained. The vertical load was applied at the beam cantilever end. The vertical load was increased monotonically until it reached $180 \mathrm{kN}$.

\subsection{Verification of FEA model}

To verify the accuracy of the FEA model, global and local behaviors of T-A model were compared with the test results. Figure 13(a) represents a comparison of the relation between the vertical load and global relative rotation of the beam. Figure 13(b) compares the relation between the vertical load and relative rotation at the beam web. In those figures, the solid lines are skeleton curves obtained from the tests, in which the influence of the bolt slippage on the skeleton curve was discarded. The dashed lines show FEA results. For both global and local rotations, the analysis results show good agreement with test results, confirming that the modeling is appropriate.

\subsection{Analysis results}

\subsubsection{Stress distribution}

Figure 14 shows the equivalent Von-Mises stress distribution of the FEA model when the vertical load at the beam end reached $180 \mathrm{kN}$. The areas in yellow and red indicate yielding. The non-intersecting models and the regular intersecting model exhibit marked differences in stress distribution. Regarding the beam flange in the nonintersecting model, it was observed that the stress of the connection plate side was greater than that of the opposite side because the bending moment of the beam acts on the column by a torque through the connection plate. In the T-A model, both the beam flanges and the column flanges around the connection area yielded. Furthermore, stress concentration is observed in red on the beam flange around the connection plate edge. In the T-B model, by contrast, the beam and column flanges around the connection area remained essentially elastic. The beam tended to yield ahead of the column. Stress concentration is not

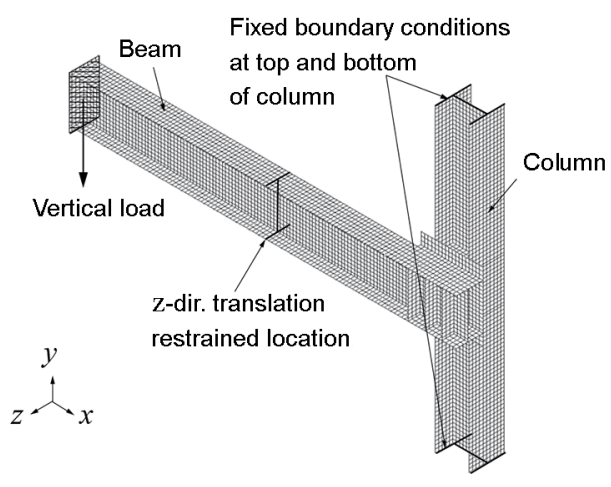

(a)

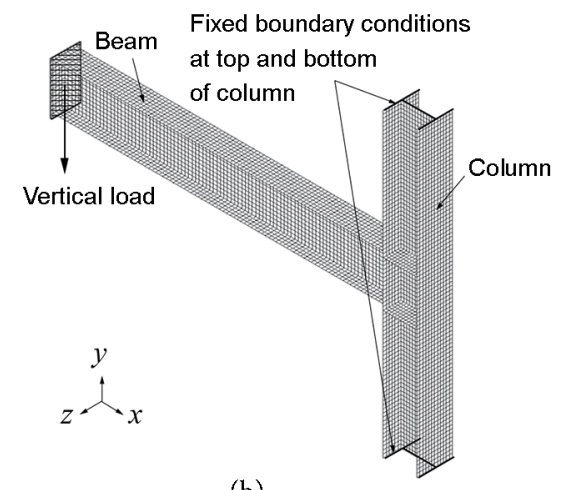

(b)

Figure 12. FEA models of the T-shaped partial frame: (a) proposed connection model (T-A, T-B);

(b) regular intersecting connection model (IS) 


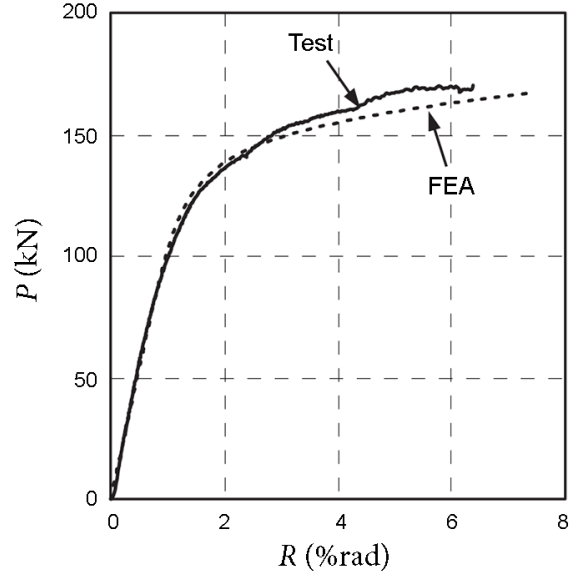

(a)

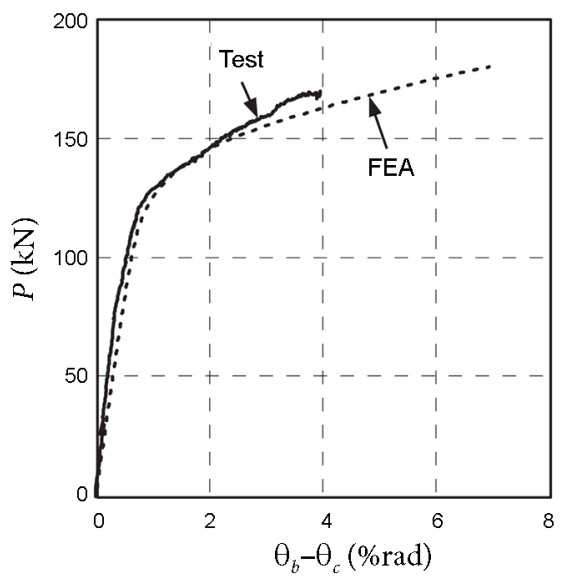

(b)

Figure 13. Comparison between FEA results and test results of T-A: (a) relation of vertical load and global relative rotation of beam; (b) relation of vertical load and relative rotation of the beam web

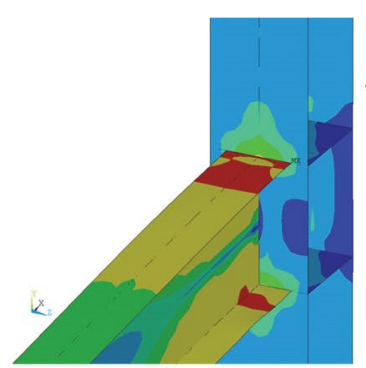

(a)

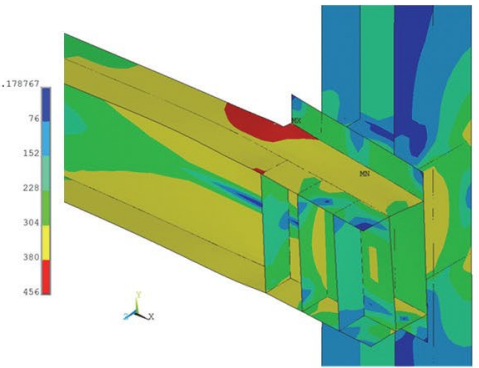

(b)

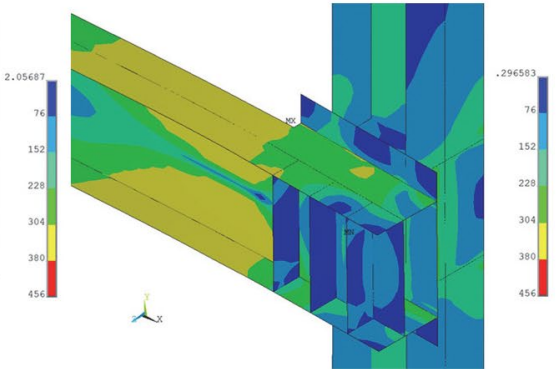

(c)

Figure 14. Von-Mises stress for $P=180 \mathrm{kN}$ : (a) IS model; (b) T-A model; (c) T-B model

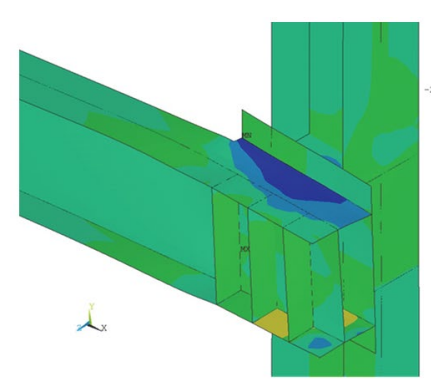

(a)

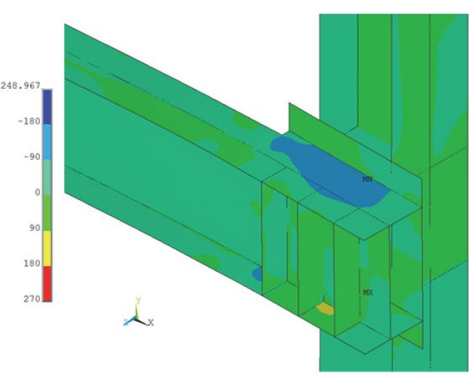

(b)

Figure 15. Shear stress $\tau_{x z}$ for $P=180 \mathrm{kN}$ : (a) T-A model; (b) T-B model

observed. This result of the T-B model is attributable to cover plates welded on the flanges.

Figure 15 shows the distribution of shear stress, $\tau_{x z}$, when the vertical load reached $180 \mathrm{kN}$. The values of $\tau_{x z}$ represent mainly the beam flange shear stress rather than the column flange shear stress that is obtained from $\tau_{y z}$. The yield shear stress was about $180 \mathrm{~N} / \mathrm{mm}^{2}$. In the T-A model, the shear stress of the beam flange area closer to the connection plate exceeds the yield stress, which can cause bolt slippage, as found for the loading test of specimen T-A. In the T-B model, by contrast, the beam flange shear stress around the connection area remained elastic attributable to the cover plates.

\subsubsection{Relation of vertical load and global relative rotation angle of beam}

Figure 16 shows the relation of vertical load and the global relative rotation angle of the beam. The initial stiffness of T-A was approximately $65 \%$ of that of IS model. The yield strength of T-A was also smaller. Elastic stiffness of the T-B model was approximately $89 \%$ of that of the IS model. The yield strength of T-B increased compared to that of 


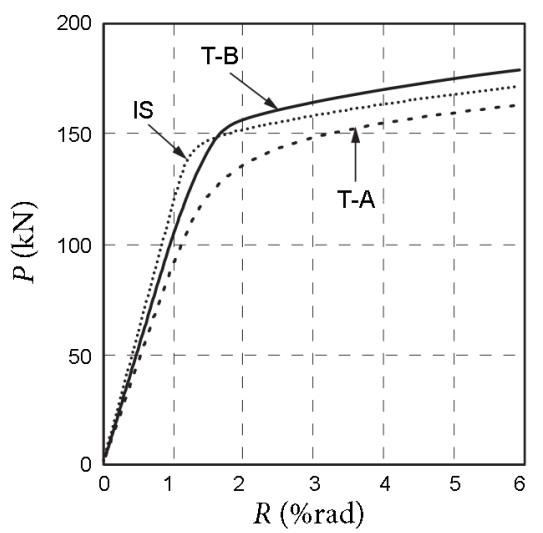

Figure 16. Relation of vertical load and global relative rotation angle of beam
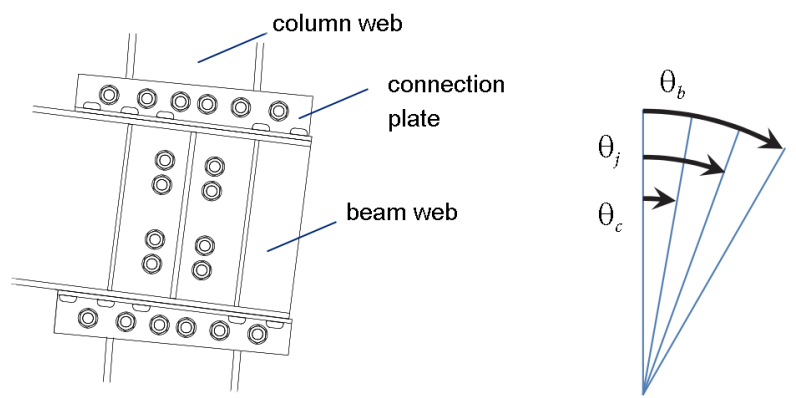

Figure 17. Definition of rotation of each component

IS model, mainly because the lateral distance between the loading point and the beam yielding point was shortened by $100 \mathrm{~mm}$ where the cover plates were welded.

\subsubsection{Rotation of each component in the connection}

FEA provided the absolute rotation angle at the beam web $\theta_{b}$, the column web $\theta_{c}$, and the connection plate $\theta_{j}$, all of which are defined in Eqns (4)-(6). Figure 17 depicts the rotations of the respective components. The difference between $\theta_{j}$ and $\theta_{c}$ is the sum of the torsional angle of column flanges $\varphi_{c f}$ and the shear deformation angle of connec-

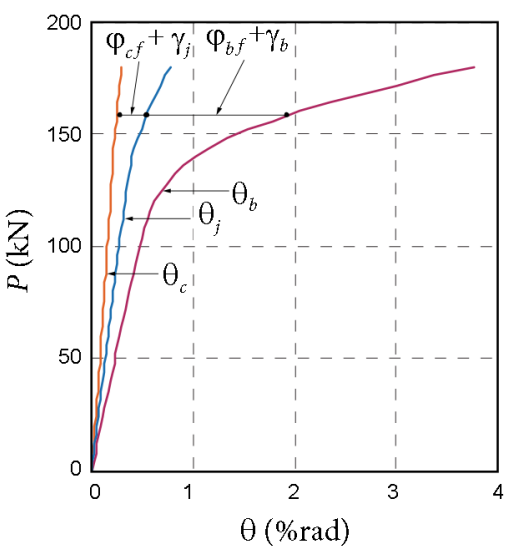

(a)

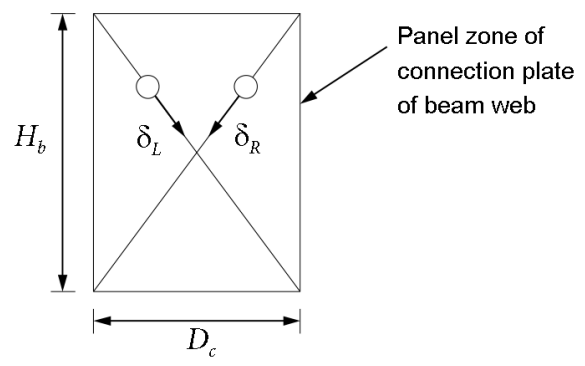

Figure 18. Notations used for calculating shear deformation angle

tion plate $\gamma_{j}$. The difference between $\theta_{b}$ and $\theta_{j}$ is the sum of the torsional angle of beam flanges $\varphi_{b f}$ and the shear deformation angle of the beam web $\gamma_{b}$. Consequently, the rotation angle of the connection, $\theta_{b}-\theta_{c}$, comprises those four angles.

The absolute rotation angles $\theta_{b}, \theta_{c}$, and $\theta_{j}$ from FEA results were obtained using the same method in the tests expressed with Eqns (4)-(6). Shear deformation angles $\gamma_{j}$ and $\gamma_{b}$ were obtained using Eqn (7):

$$
\gamma=\frac{\sqrt{H_{b}^{2}+D_{c}^{2}}\left(\delta_{R}-\delta_{L}\right)}{2 H_{b} \cdot D_{c}},
$$

where notations in Eqn (7) are presented in Figure 18, in which $\delta_{L}$ and $\delta_{R}$ denote the deformation of the panel zone diagonal; $H_{b}$ and $D_{c}$ respectively denote the beam height and column width. The values of $\delta_{L}$ and $\delta_{R}$ were calculated using the displacements of four nodes at the corner.

The torsional angles $\varphi_{b f}$ and $\varphi_{c f}$ were calculated by subtracting shear deformation angles from the overall rotation angles between the concerned components as shown below:

$$
\varphi_{b f}=\theta_{b}-\theta_{j}-\gamma_{b}, \varphi_{c f}=\theta_{j}-\theta_{c}-\gamma_{j} .
$$

Figure 19 shows the relations of vertical load and rotations $\theta_{b}, \theta_{c}$, and $\theta_{j}$. Figure 20 presents variation of rotation ratio of each component to the total connection rotation. First, in the elastic range, proportions of those four de-

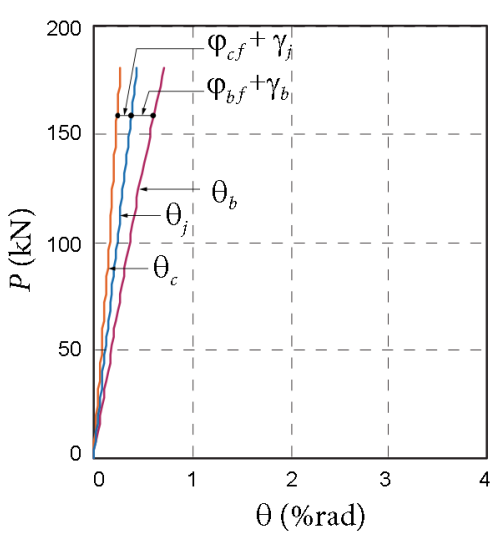

(b)

Figure 19. Relation of the rotation angle of each component and the vertical load: (a) T-A model; (b) T-B model 


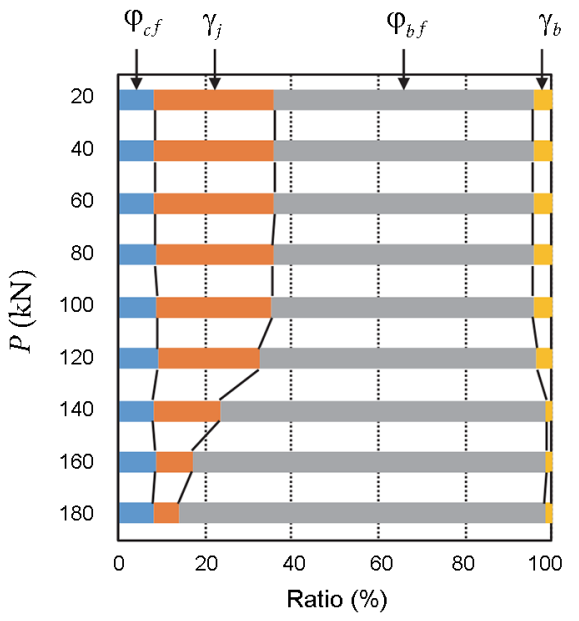

(a)

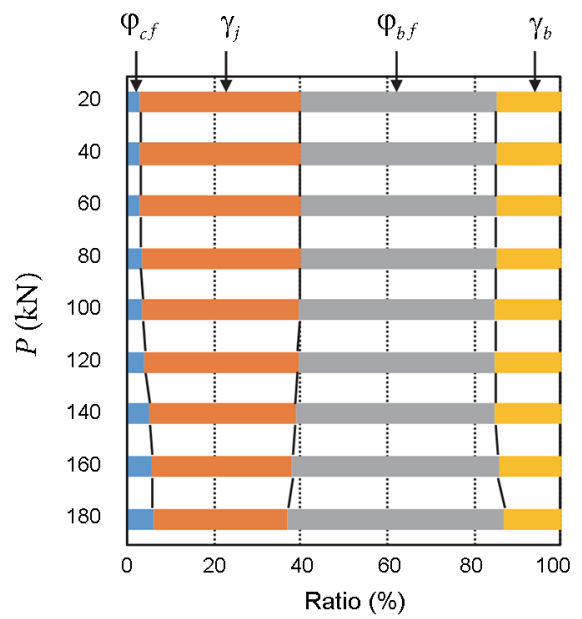

(b)

Figure 20. Variation of rotation ratio of each component: (a) T-A model; (b) T-B model

flection angles remained fundamentally constant, among which $\varphi_{c f}$ and $\gamma_{b}$ were the minor contributors, whereas $\varphi_{b f}$ was dominant. When plastic deformation occurred in the T-A model, the ratio of $\varphi_{b f}$ continued increasing up to $80 \%$ as a result of the shear yielding of the beam flanges. The ratio of the shear deformation angle of the connection plate, which was the secondary large value in the elastic range, decreased in the plastic range because the connection plate remained elastic. By contrast, variation of the proportion is small until the final stage in the T-B model, where the connection area remained elastic by strengthening flanges with cover plates.

\section{Application of the proposed connection in moment-resisting frames}

\subsection{Frame models}

This section demonstrates the structural behavior of moment resisting frames including the proposed connections. Significant torsional deformation of the girder might occur because of eccentricity between the girder and column. Therefore, additional torsional constraint might be necessary for the girders. Effects of floor slabs were not considered in this study; instead, the secondary beams were regarded as efficient restrainers. Pushover analyses of a 3D frame model with various configurations of the secondary beams were conducted.

The benchmark model is a two-story steel frame with two spans of $5 \mathrm{~m}$ in the X-direction (moment frame) and one span of $6 \mathrm{~m}$ in the Y-direction (braced frame), as presented in Figure 21. The girders in X-dir. do not intersect with the columns. The material properties and dimensions of the columns, girders and the strengthening detail at their flanges are identical to those of the T-B model. Cross-section dimensions of the secondary beams are $\mathrm{H}-200 \times 100 \times 5.5 \times 8$.
The five frame models described below were created. Their static behaviors under lateral loads in X-dir. were compared.

- F-BO: frame without secondary beams;

- F-BM: frame with secondary beams connected to the midpoints of the girders;

- F-BT: frame with secondary beams connected to the trisection points of the girders;

- F-BP: frame with secondary beams connected to the plastic hinge areas of the girders;

- F-IS: frame with regular intersecting beam-to-column connections without secondary beams.

\subsection{Simplified model of proposed connections for 3D frame analysis}

The elastic-plastic behavior of the proposed connection can be analyzed in detail using shell elements. However, the analysis time gets longer if the shell elements are employed in the 3D frame analysis. One solution for decreasing the analysis time is to use the center-line beam elements for each structural component. Bolted beam-tocolumn connections are classifiable into semi-rigid connections (Chen \& Kishi, 1989) and thus extensive investigations have been conducted for modeling the connections and developing analysis methods (Bayo, Cabrero, \& Gil, 2006; Pirmoz, Khoei, Mohammadrezapour, \& Daryan, 2009; Daryan, Sadri, H. Saberi, V. Saberi, \& Moghadas, 2014). For the typical bolted connections, the rotational spring models can be constructed by combining the component springs whose stiffness equations have been presented in Eurocode 3 (2005). Instead of the rotational springs, this study incorporates torsion spring models for representing the proposed connections in frame analysis because the bending moment of the beam acts on the column by a torque through the proposed connection.

Figure 22(a) presents the simplified center-line model of the T-shaped partial frame. Element BC, which repre- 


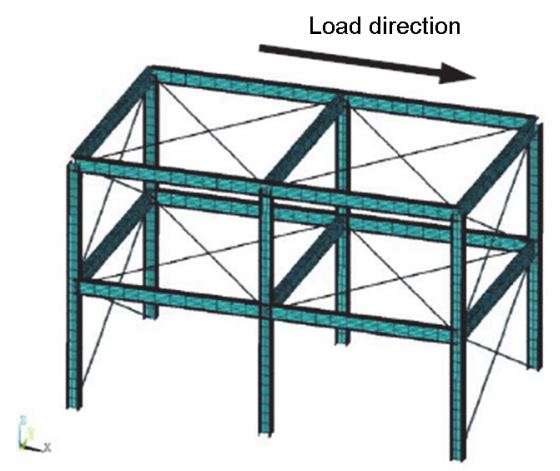

(a)

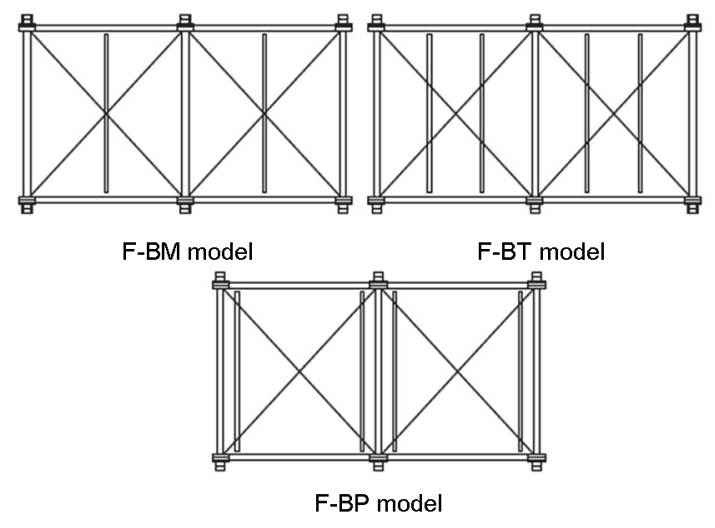

(b)
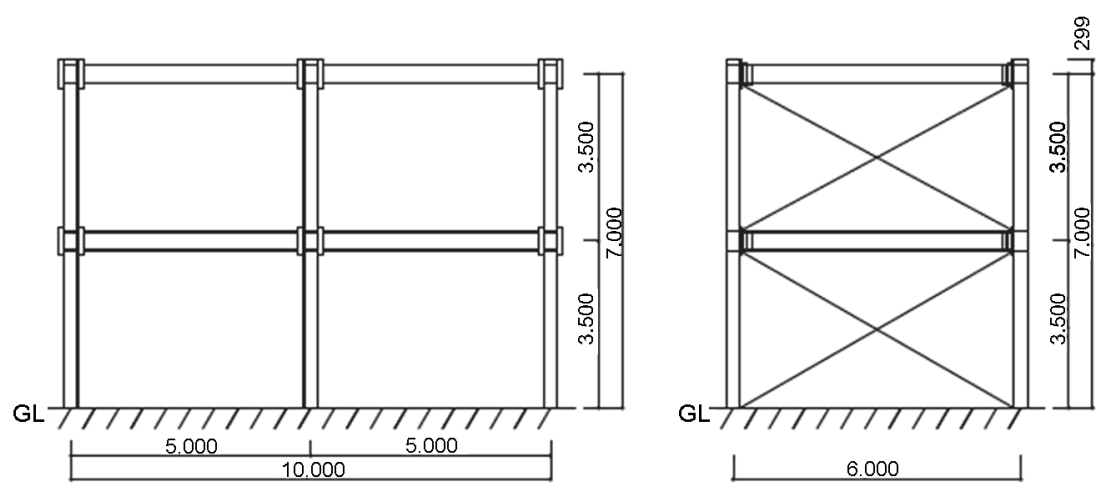

(c)

Figure 21. Frame models with various secondary beam configurations: (a) perspective view (F-BO); (b) plan configurations of secondary beams; (c) elevation view (units: $\mathrm{mm}$ )

sents the torsion spring model for the connection, is composed of a beam element assigned as a circular cross section. The torsional stiffness of $\mathrm{BC}$ is given to be identical to that of the proposed connection in the model employing shell elements. Uniform torsional deformation appears along the axial direction of $\mathrm{BC}$ when it is subjected to a torsional moment $T$ which results from the vertical load $P$ at the cantilever end of the beam. Equilibrium and constitutive relations give the diameter $D$ of the element $\mathrm{BC}$ from Eqns (9)-(11). The final expression for $D$ is presented in Eqn (12):

$$
\begin{aligned}
& T=P L ; \\
& T=G \frac{\pi D^{4}}{32} \theta ; \\
& \varphi=\theta h ; \\
& D=\sqrt[4]{\frac{32 P L}{\pi G \theta}},
\end{aligned}
$$

where $L$ signifies the distance from the loading point to the column center line. $G$ stands for the elastic shear modulus; which is calculated from equation $G=E /(2(1+v))$ 


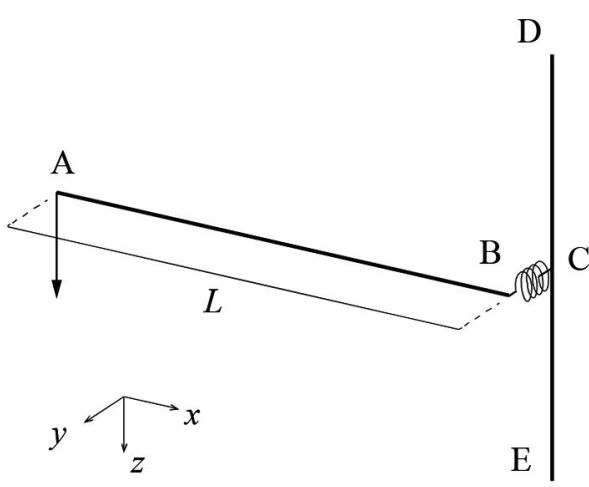

(a)

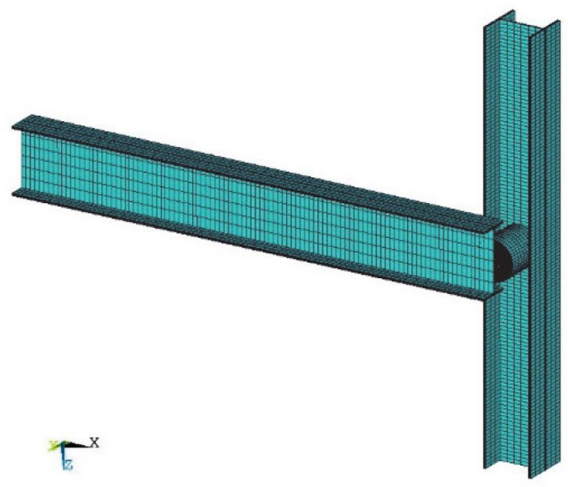

(b)

Figure 22. Simplified frame model: (a) center-line model with a torsion spring; (b) image of sections of each element

with $E=2.05 \times 10^{5} \mathrm{~N} / \mathrm{mm}^{2}$ and $\mathrm{v}=0.3 . \theta$ expresses the torsional deformation in a unit length of element $\mathrm{BC} ; \varphi$ is the torsional deformation of the element BC.

When the T-B model was subjected to $P=60 \mathrm{kN}$, the relative rotation between the beam and the column was obtained as $\varphi=0.0019$ rad from FEA using the shell elements model used in the previous section. Consequently, the diameter of element BC was calculated as $244 \mathrm{~mm}$ using Eqn (12). Analysis results showed that the stiffness and yield strength of the simplified center-line beam elements model well matched with the shell elements model, which confirmed the validity of the simplified model. At the present stage of research, this simplification procedure is recommended to be used for design practice for frames adopting the proposed connections.

Figure 22(b) shows the section image that is visualized by the ANSYS command. Frame deformations as shown later in Figure 24 are also drawn by this command.

\subsection{Analysis setting}

The beams, columns and simplified connection models were modeled using the two-node beam 188 element in ANSYS. Young's modulus of the beams and columns elements was $2.05 \times 10^{5} \mathrm{~N} / \mathrm{mm}^{2}$ and their Poisson's ratio was 0.3 . The elements at the panel zone areas in both beams and columns were assigned to be rigid. Bottoms of the columns in the first story were fully restrained. Von-Mises yield criterion was adopted to determine the beginning of yielding of the steel material. Yielding stress of beams and columns were assigned as $304 \mathrm{~N} / \mathrm{mm}^{2}$ and $320 \mathrm{~N} / \mathrm{mm}^{2}$, respectively. Bilinear relation was assumed for the stressstrain relation of the steel material with a strain-hardening ratio of 0.01. Elastic material was used for connection elements, because the detailed shell elements analysis in Section 3 had verified that all the connection components could remain elastic in the T-B model.

Pushover analyses were conducted for each frame under the lateral loads that were distributed according to the Japanese seismic code. The lateral loads were uniformly distributed on the six nodes at the beam-to-column connections on each floor.

\subsection{Analysis results}

\subsubsection{Relation of story shear and story drift}

Figure 23 shows the relation of story shear $Q$ and story drift angle $r$ of F-IS, F-BO, and F-BP models. Story stiffness of F-BP model was the greatest among the non-intersecting models, which was around $80 \%$ of that of the intersecting model F-IS. Furthermore, the F-BP model showed superior ductility and stable post-yield behavior compared to other non-intersecting models. For the F-BO model, the analysis was terminated much earlier due to the large deformation of the girders as shown in Figure 24(a). The analysis for the F-IS model was also terminated earlier due to the lateral-torsional buckling of girders.

\subsubsection{Von-Mises stress distribution and deformation}

Figures 24(a)-24(d) show the Von-Mises stress distribution of the deformed models when the base shear reached $1307 \mathrm{kN}$. In these figures, deformations were magnified to 20 times their actual values. Stress at the connection

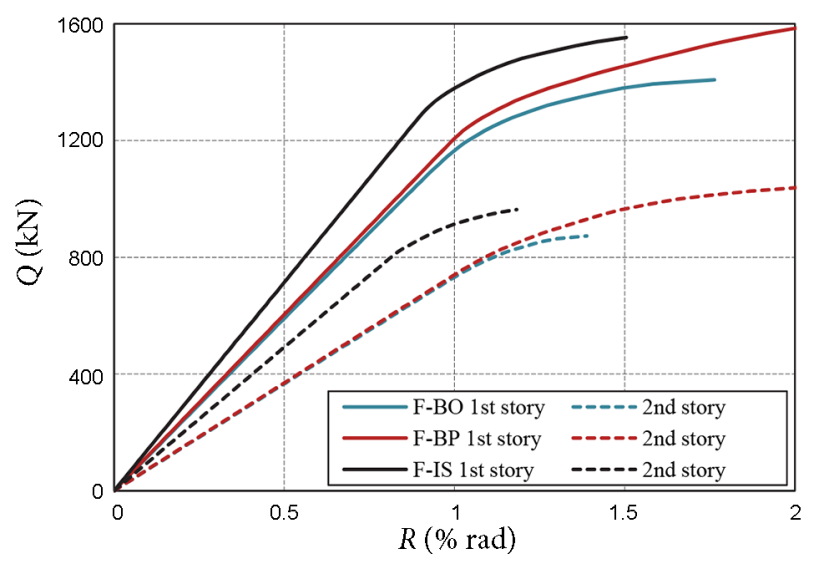

Figure 23. Relation between story shear and story drift angle in F-BO, F-BP, and F-IS models 


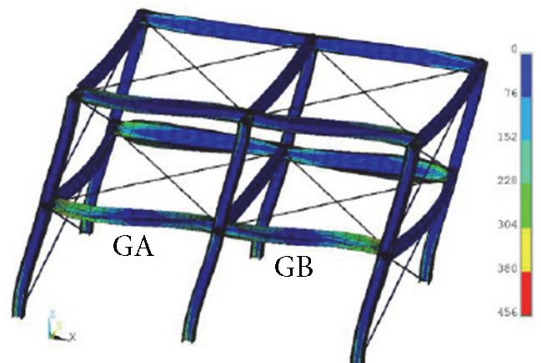

(a)

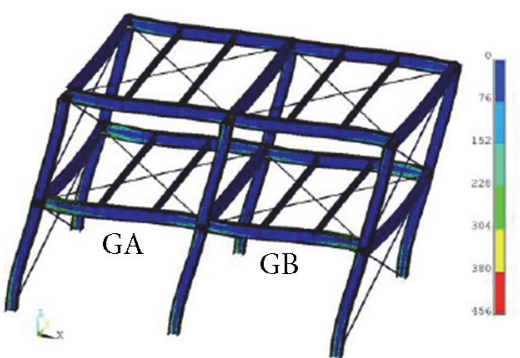

(c)

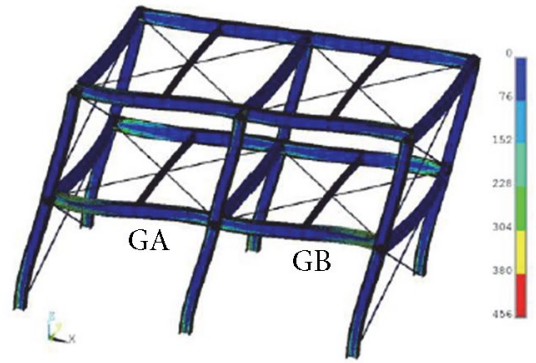

(b)

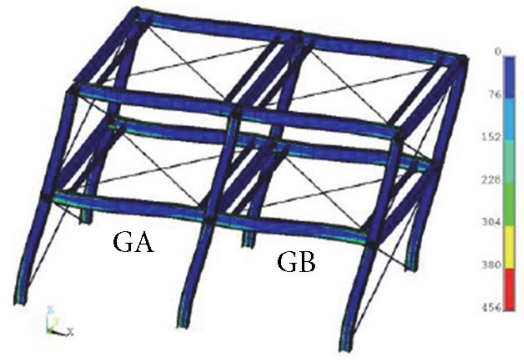

(d)

Figure 24. Von-Mises stress distribution of frame models with various configurations: (a) F-BO model; (b) F-BM model; (c) F-BT model; (d) F-BP model

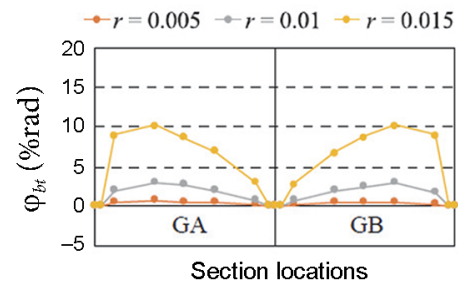

(a)

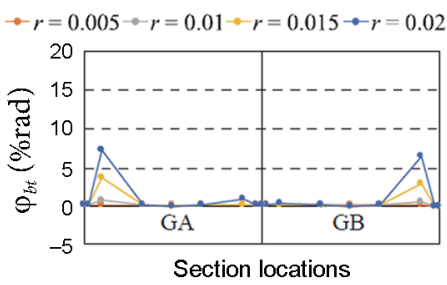

(c)

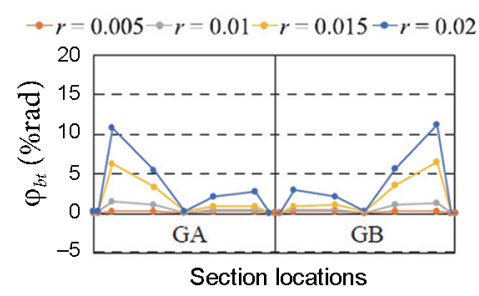

(b)

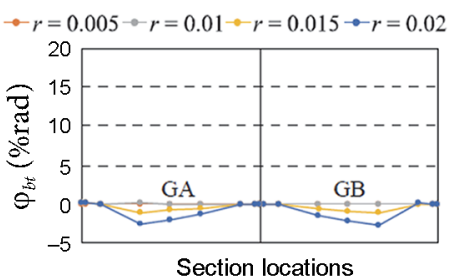

(d)

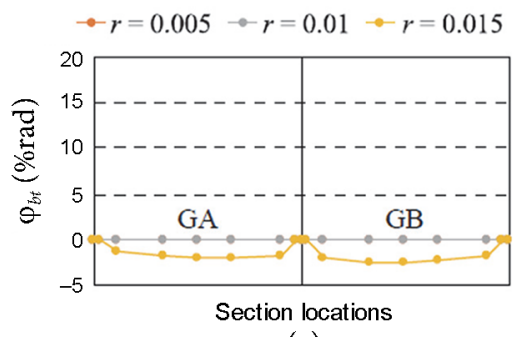

(e)

Figure 25. Torsional angle of girders with various configurations of secondary beams: (a) F-BO model; (b) F-BM model; (c) F-BT model; (d) F-BP model; (e) F-IS model 


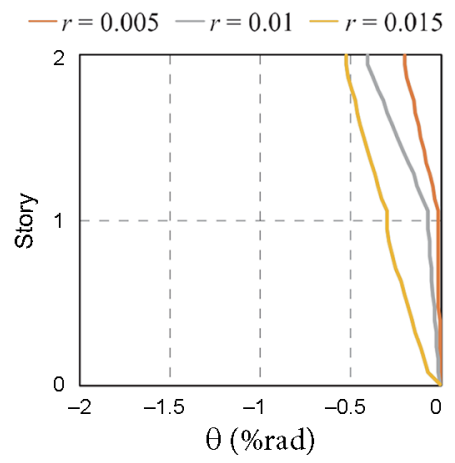

(a-1) Middle column

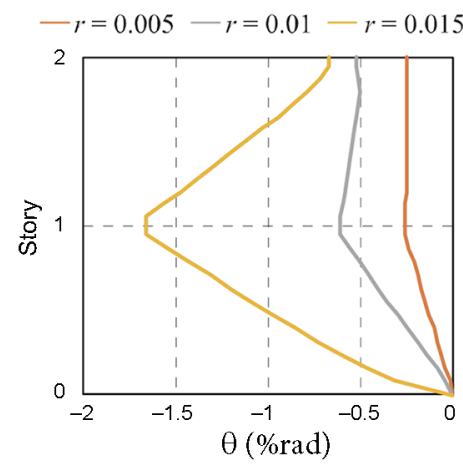

(a-2) Corner column

(a)

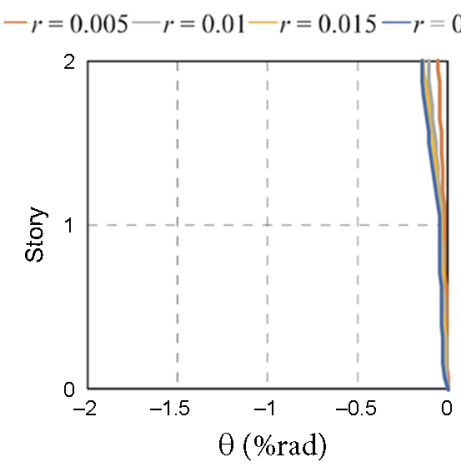

(b-1) Middle column (b)

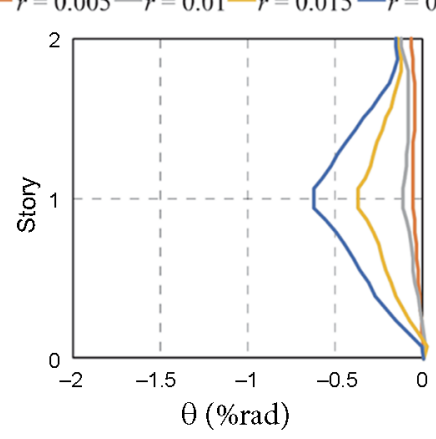

(b-2) Corner column

Figure 26. Torsional angle of columns for F-BO and F-BP models: (a) F-BO model;

(b) F-BP model

areas and at the bottoms of columns was greater than in other areas. Torsion of the X-dir. girders was observed clearly, particularly in the F-BO model. By comparing Figure 24(a) with 24(b)-24(d), it was revealed that high stress zones of the girders were effectively reduced by adding the secondary beams. Girder-end torsional deformations of the F-BP model were the smallest and the deflections of the Y-dir. girders were also reduced in the F-BP model.

\subsubsection{Torsion of girders and columns}

Figure 25 shows torsional angle distributions along girders GA and GB at first story drift angles of $0.005,0.01,0.015$, and 0.02 rad. In the F-BO model, large torsion of girders appeared at the early stage. This behavior was induced by the large eccentricity of the non-intersecting connections. It is observed from Figures 25(b)-25(d) that the secondary beams reduce the girder torsion. Figure 25(b) and 25(c) reveal that the girder torsional angles increase more at the portions near the corner columns than near the middle column. Placing secondary beams at the plastic hinge areas of the girder for the F-BP model is the most efficient configuration and achieved even smaller torsion compared to F-IS model in which lateral-torsional buckling occurred beyond the elastic limit.

Figure 26 shows the torsional angle along columns at first story drift angles of $0.005,0.01,0.015$, and $0.02 \mathrm{rad}$. The column torsion appeared largely for the F-BO model especially in the corner column. It can be mentioned that the eccentricity effects of the non-intersecting connec- tions possibly influence both girder and column torsional behavior. The column torsions for F-BP model were sufficiently reduced by the properly placed secondary beams.

\section{Conclusions}

This research proposed bolted beam-to-column connections of two types for cases in which the beam does not intersect with the column. Their structural capacity was verified by cyclic loading tests for T-shaped partial frame specimens. More detailed discussions were conducted based on FEA of the T-shaped frames. Application of the proposed connection in moment-resisting frames was also discussed based on pushover analyses of 3D frame models. A regular intersecting connection was used for comparison study for both the connection level and the frame level. The main findings are summarized as follows.

1. From the T-shaped specimen tests, the proposed connections showed sufficient plastic deformation capacity. However, bolt slippage behaviors on the beam flanges were observed in specimen T-A, which indicated that the shear-resisting capacity of the beam and column flanges were fundamentally important for achieving a desired level of connection stiffness. On the contrary, The hysteretic behavior of specimen T-B was improved dramatically, which verified the efficiency of using cover plates to strengthen its beam and column flanges around the connection. 
2. For a deeper understanding of the proposed connections, FEA models of the test specimens were created and verified by the test results. The analysis results of two types of proposed connections revealed the improvement of stress distribution by the cover plates. To investigate the connection rotational behavior in detail, the connection rotation was divided into four components; the torsional angle of column flanges, the shear deformation angle of connection plate, the torsional angle of beam flanges and the shear deformation angle of the beam web. The analysis results provided the variations of rotation ratio of each component and revealed that the torsional angle of beam flanges was the largest.

3. A FEA model of a regular intersecting connection was also created for comparison. Comparisons of the vertical load and beam rotation angle relations demonstrated that the stiffness of the non-intersecting beam and column connection can reach $89 \%$ of that of the intersecting connection.

4. For the 3D frame analysis using the center-line beam elements, torsion spring models were incorporated to represent the proposed connections because the bending moment of the beam acts on the column by a torque through the connection. The properties of the torsion spring were obtained from the finite element analysis of the non-intersecting connection models using shell elements.

5. Pushover analyses of the frame models showed that the story stiffness of a two-story two-span frame adopting the non-intersecting beam and column connections was around $80 \%$ of that of a frame adopting intersecting connections. It was found that the transverse constraining by secondary beams are effective to reduce the girder torsion induced by eccentricity of the non-intersecting connections. To examine the optimal placement of the secondary beams, some frame models with different configurations were analysed. Analysis results showed that equipping secondary beams at the plastic hinge areas of girders can restrain the torsion of girders and columns efficiently into a similar level as that of regular intersecting connections.

6. In conclusion, the proposed non-intersecting beam and column connection is able to provide sufficient stiffness and deformation capacity in moment-resisting frames if the details of beams and columns at the connection area are carefully designed and sufficient transverse constraining for the girders is ensured.

\section{Funding}

This work was supported in part by JSPS KAKENHI Grant Number JP15K06296.

\section{Author contributions}

H. Tagawa conceived the study and was responsible for the design and development of data analysis. S. Yoshida and Y. Nakaoka were responsible for data collection and analysis. H. Tagawa, S. Yoshida, Y. Nakaoka, and X. Chen were responsible for data interpretation. $\mathrm{X}$. Chen wrote the first draft of the article.

\section{Disclosure statement}

This research has no competing financial, professional, or personal interests from other parties.

\section{References}

AIJ. (2012). Recommendation for design of connections in steel structures ( $3^{\text {rd }}$ ed.). Tokyo: Architectural Institute of Japan (in Japanese).

ANSYS 15.0. (2014). Users' manual. ANSYS Inc., USA.

Asran, A. G., El-Esnawi, H. H., \& Fayed, S. (2017). Experimental investigation of RC exterior beam column connection with eccentric beam subjected to reversible quasi static loads. Civil Engineering Journal, 3(4), 221-236.

Bayo, E., Cabrero, J. M., \& Gil, B. (2006). An effective component-based method to model semi-rigid connections for the global analysis of steel and composite structures. Engineering Structures, 28(1), 97-108. https://doi.org/10.1016/j.engstruct.2005.08.001

Canbolat, B. B., \& Wight, J. K. (2008). Experimental investigation on seismic behavior of eccentric reinforced concrete beamcolumn-slab connections. ACI Structural Journal, 105(2), 154-162.

Chen, W. F., \& Kishi, N. (1989). Semirigid steel beam-to-column connections: Data base and modeling. Journal of Structural Engineering, 115(1), 105-119. https://doi.org/10.1061/(ASCE)0733-9445(1989)115:1(105)

Daryan, A. S., Sadri, M., Saberi, H., Saberi, V., \& Moghadas, A. B. (2014). Behavior of semi-rigid connections and semi-rigid frames. The Structural Design of Tall and Special Buildings, 23, 210-238. https://doi.org/10.1002/tal.1032

Eurocode 3. (2005). Design of steel structures, part 1-8: Design of joints (EN 1993-1-8:2005). Brussels: European Committee for Standardization (CEN).

Grogan, W., \& Surtees, J. O. (1999). Experimental behaviour of end plate connections reinforced with bolted backing angles. Journal of Constructional Steel Research, 50, 71-96. https://doi.org/10.1016/S0143-974X(98)00227-2

Lafave, J. M., Bonacci, J. F., Burak, B., \& Shin, M. (2005). Eccentric beam-column connections. Concrete International, 27(9), 58-62.

Liu, C., \& Tagawa, H. (2009). Panel zone strength of eccentric beam-to-wide flange column connections. Journal of Structural and Construction Engineering, Transaction of AIJ, 636, 375-384 (in Japanese). https://doi.org/10.3130/aijs.74.375

Masuda, H., Tanaka, A., Ishimaru, R., Hirai, K., \& Sasaji, S. (2000). Experimental study of the statical characteristics of perimeter beam-to-SHS column connections using vertical stiffener plates. Journal of Structural and Construction Engineering, Transaction of AIJ, 534, 167-174 (in Japanese). 
Miki, N., Yamada, S., Kishiki, S., Jiao, Y., \& Hasegawa, T. (2015). Structural behavior of eccentric beam-to-RHS column connections. Journal of Structural and Construction Engineering, Transaction of AIJ, 710, 669-679 (in Japanese). https://doi.org/10.3130/aijs.80.669

Mirghaderi, S. R., \& Renani, M. D. (2008). The rigid seismic connection of continuous beams to column. Journal of Constructional Steel Research, 64(12), 1516-1529. https://doi.org/10.1016/j.jcsr.2008.01.015

Oshida, M., Ichinohe, Y., Saito, K., Fultmoto, T., Tachibana, M., \& Morita, K. (2005). Experimental study on frame behaviors of connections with eccentricity between steel beam and concrete-filled square tubular steel column reinforced with through diaphragm. Steel Construction Engineering, 12, $17-$ 30 (in Japanese). https://doi.org/10.11273/jssc1994.12.48_17

Pirmoz, A., Khoei, A. S., Mohammadrezapour, E., \& Daryan, A. S. (2009). Moment-rotation behavior of bolted top-seat angle connections. Journal of Constructional Steel Research, 65(4), 973-984. https://doi.org/10.1016/j.jcsr.2008.08.011

Shi, Z., \& Fan, J. (2018). Analytical investigation on effective elastic stiffness of eccentric steel beam-column joints. Advances in Structural Engineering, 21(1), 125-137.

https://doi.org/10.1177/1369433217711619
Soya, K., Sato, E., Komuro, T., Yasuda, S., \& Nishimoto, S. (2010). Narihara H. Structural performance of eccentric beam-column joints composed of reinforced concrete columns and steel beams - Part 1 Outline of experiment, and Part 2 Evaluation of stiffness and strength. In Summaries of Technical Papers of Annual Meeting. AIJ (pp. 1307-1310) (in Japanese). Tagawa, H., \& Liu, Y. (2014). Stiffening of bolted end-plate connections with steel member assemblies. Journal of Constructional Steel Research, 103, 190-199. https://doi.org/10.1016/j.jcsr.2014.09.005

Vollum, R. L., \& Newman, J. B. (1999). Towards the design of reinforced concrete eccentric beam-column joints. Magazine of Concrete Research, 51(6), 397-407. https://doi.org/10.1680/macr.1999.51.6.397

Yamada, S., Yoshie, K., Kouno, T., \& Kojima, D. (2010). Experimental study on the structural performance of non-intersection type steel beam-to-column connection. Journal of Structural and Construction Engineering, Transaction of AIJ, 656, 1901-1908 (in Japanese). https://doi.org/10.3130/aijs.75.1901 